\title{
CuLtURA, EDUCACIÓN Y EMPLEABILIDAD EN EL CONTEXTO GLOBAL
}

CULTURE, EDUCATION AND EMPLOYABILITY IN THE GLOBAL CONTEXT

Fernando González Figueroa Profesor investigador de tiempo completo de la Facultad de Ciencias Administrativas de la Universidad La Salle

Pachuca

fgonzalez@lasallep.edu.mx

\section{Resumen}

El artículo plantea algunas reflexiones entre educación, cultura y empleabilidad, en crecientes procesos de globalización. Para ello se analiza críticamente los efectos de la globalización en el ámbito educativo; es decir, cómo a partir de la lógica de la economía de mercado se homogeneiza las políticas y programas educativos, con lo cual las Instituciones de Educación Superior [IES], se han reestructurado para hacer frente a los cambios del mercado de trabajo. El documento incorpora reflexiones desde perspectivas, histórica, cultural, antropológica, económica y sociológica; temáticas que están implícitas en los contextos educativos. Artículo concluido en enero de 2012.

Palabras clave: Globalización, educación, cultura, empleabilidad, competencias

ABSTRACT 
THE ARTICLE REFLECTS ABOUT EDUCATION, CULTURE AND EMPLOYABILITY, INSIDE IN INCREASING GLOBALIZATION PROCESSES. WE EXAMINE CRITICALLY THE EFFECTS OF GLOBALIZATION IN EDUCATION, THAT IS, HOW FROM THE LOGIC OF THE MARKET ECONOMY POLICIES AND EDUCATIONAL PROGRAMS ARE HOMOGENIZED, THEREBY HIGHER EDUCATION INSTITUTIONS (IES), HAVE BEEN RESTRUCTURED TO MEET THE CHANGES OF THE LABOR MARKET. THE DOCUMENT INCORPORATES REFLECTIONS FROM HISTORICAL, CULTURAL, ANTHROPOLOGICAL, ECONOMIC AND SOCIOLOGICAL PERSPECTIVES; THEMES THAT ARE IMPLICIT IN EDUCATIONAL CONTEXTS. ARTICLE COMPLETED IN JANUARY 2012.

KEYWORDS: GLOBALIZATION, EDUCATION, CULTURE, EMPLOYABILITY, SKILLS

\section{INTRODUCCIÓN}

Reflexionar sobre el impacto que ha tenido la globalización en la educación, es una temática insoslayable, especialmente para quienes estamos vinculados con la docencia, pero además, estamos interesados por una educación de calidad que permita formar jóvenes críticos, que sepan adaptarse a los cambios que el mercado laboral exige; pero sobre todo que mejore los niveles de bienestar para la sociedad.

En este documento, presento en la primera parte un breve marco histórico de lo que ha significado el desarrollo de la globalización, donde sostengo que tal fenómeno viene alienado al sistema capitalista de producción. En seguida 
abordo la visión antropológica y cultural donde no sólo analizo cómo la globalización ha permeado la cultura e identidad de los individuos, sino también planteo algunas advertencias metodológicas que se hacen en torno al abordaje del estudio de la interculturalidad. Después analizo cómo la educación, particularmente la educación superior, se ha visto afectada por el fenómeno de la globalización $y$, en ese sentido ha incentivado el desarrollo de competencias profesionales y, junto a eso la empleabilidad. Finalmente presento algunas conclusiones y las referencias consultadas.

\section{Preámbulo}

Derivado de las grandes transformaciones que ha experimentado la economía mundial y especialmente con el incremento de las redes de comunicación y la tecnología; los mercados de trabajo también se han trasformado y ahora han cambiado los procedimientos para la contratación de mano de obra. De ahí que las universidades, ahora busquen nuevos mecanismos para adaptar la oferta educativa a las necesidades del mercado laboral. Sin embargo, habría que reconocer que educación y mercado son dos fenómenos que en la práctica no están debidamente articulados, simplemente porque llevan ritmos y tiempos distintos ${ }^{1}$ (Martuscelli y Martínez, 2002).

Si partimos de que todo sistema económico se encuentra organizado en función del qué, cómo y para quién producir; con determinadas excepciones, los sistemas

\footnotetext{
${ }^{1}$ Esto significa que las universidades siempre llevan unos pasos atrás respecto al dinamismo que marcan los mercados.
} 
económicos modernos producen para el mercado. En este sentido, es el mercado de bienes y servicios el que dicta la dinámica, la movilidad y la velocidad con que han de moverse los recursos. De ahí que el mercado de trabajo mantenga una dinámica alineada al mercado de bienes. $^{2}$ Por ejemplo, hasta la década de los ochenta el empleo era más estable e invariablemente era vitalicio, pero con la crisis que experimentaron la mayoría de los países en esa década, especialmente los de A.L., se incrementaron las tasas de desempleo, se debilitaron los sindicatos y comenzaron a cambiar las relaciones laborales al interior de las empresas. La transición hacia la flexibilidad laboral, la polivalencia del trabajador, la duración de la jornada de trabajo, el perfil de contratación, entre varios aspectos, han sido los nuevos mecanismos que hoy utilizan las empresas en el proceso de contratación de mano de obra (De la Garza, 2000; Ruesga y Murayama, 2000; y Coello, 2009).

\section{Breve contexto histórico de la globalización}

En principio habría que señalar que la globalización es un fenómeno <inacabado> que hoy día se utiliza para referirse a los procesos de integración en todas sus modalidades, especialmente en lo económico, lo político, lo social y lo cultural. Sin embargo, habría que decir, que no es reciente. Su aparición se remonta a los tiempos de las expediciones occidentales y a los viajes a las indias orientales, particularmente a China. ${ }^{3}$

\footnotetext{
${ }^{2}$ Con referencia a la lógica económica, el mercado de mano de obra pasa a formar parte del mercado de recursos, donde las empresas se abastecen y obtienen los medios que utilizarán para la transformación y generación de productos nuevos; es decir, las mercancías que se enviarán al mercado.

${ }^{3} \mathrm{Sin}$ duda, uno de los registros documentados con los que cuenta la historia, es el viaje de Marco Polo que realizó en el Siglo XIII a China siguiendo la ruta de la seda (Yamashita, 2004).
} 
Con esta postura coinciden Braudel (1986), Ferrer (1996), Wallerstein (1979), Flores y Mariña (2000), Beck (1998), entre otros. Por ejemplo, Braudel hace ver que el proceso de gestación de la globalización se da en el Siglo XIII y su florecimiento entre los Siglos XV y XVIII; al respecto señala:

Durante los siglos del antiguo régimen, entre 1400 y 1800 , se trata aún de una economía de intercambio llena de imperfecciones. Sin duda, y debido a sus orígenes, esta economía se pierde en la noche de los tiempos, pero no logra asociar toda la producción a todo el consumo, ya que una inmensa parte de aquélla se pierde en el auto-consumo, de la familia o del pueblo, y no entra en el circuito del mercado (Braudel, 1986, p. 9).

Para Braudel, está claro que este proceso va amalgamado al surgimiento del sistema capitalista de producción, el cual ve en la economía de mercado el medio propicio para movilizar los recursos y hacer lo que Marx llamó: la conversión del dinero en capital; es decir, todo lo que queda fuera del mercado adquiere únicamente un valor de uso y todo lo que queda dentro adquiere un valor de cambio. ${ }^{4}$

En la misma lógica marxista, Beck fija su postura y sostiene que la globalización inició su ascenso cuando la burguesía imprimió un sesgo cosmopolita a la producción y al consumo de todos los países. Agrega que "la explotación del mercado mundial se remonta a una fecha mucho más vieja de lo que suele aceptar la memoria

\footnotetext{
${ }^{4}$ En este tiempo la llamada economía de mercado se encontraba en proceso de conformación. La aparición de un número importante de burgos y ciudades era necesario para organizar la producción y orientarla al consumo en masa. Aunque cabe hacer la aclaración que en este tiempo, la economía de mercado se encontraba en un estado imperfecto ([Braudel, 1986).
} 
<miope> del debate público" (Beck, 1998, p. 45). Y es en este devenir histórico que para él no existe una sola sociedad global; sino dos y en reciproca competencia; es decir, por un lado, la sociedad de los Estados nacionales $y$, por otro lado, las múltiples organizaciones transnacionales, a quienes identifica como actores, grupos e individuos que entretejen un vasto entramado de relaciones sociales. Pero justamente, es el Estado nacional en quien recae la responsabilidad de organizar y regular a la sociedad de mercado; de otra forma habría desorden y caos.

Por su parte, Ferrer (1986) aduce que la globalización tiene una antigüedad de cinco siglos y fue liderada en sus inicios por las expediciones marítimas de España y Portugal, y después por Gran Bretaña, Francia y Holanda. Para él, este fue el primer sistema internacional de alcance planetario y coincidió justamente con el aumento de la productividad, derivada del progreso tecnológico que ocurrió en la Baja Edad Media. Agrega que estos avances que posibilitaron las mejoras en la navegación y la guerra no habrían sido posibles sin el desarrollo del conocimiento científico. ${ }^{5}$

En este sentido, los autores mencionados, coinciden en que la globalización surcó su desarrollo a la par del capitalismo. Por lo tanto, la historia de la globalización es la historia del capitalismo; el cual desde sus inicios usó a la economía de mercado como medio de conversión e

\footnotetext{
${ }^{5}$ Hasta la Baja Edad Media, el crecimiento era lento y homogéneo en las distintas regiones, pero con los avances científicos se abrieron las diferencias en la disposición de recursos e ingresos, de ahí que la hegemonía que tenían Portugal y España cambiaría de posición geográfica.
} 
intercambio para la asignación "racional" de recursos. ${ }^{6} \mathrm{De}$ hecho ya desde el mercantilismo en el Siglo XV (en sus distintas modalidades) y posteriormente con la fisiocracia en el Siglo XVII y XVIII, el sistema capitalista iría adquiriendo forma y reuniría las condiciones históricas, económicas y normativas que le darían el poder hegemónico que hoy ha alcanzado. ${ }^{7}$ De ahí que Wallerstein (1990) al retomar los planteamientos de Marx, haya pensado en el capitalismo como "un sistema basado entre productores libres que utilizan trabajo libre y mercancías libres: <libre> significa aquí su disponibilidad para la venta y la compra en un mercado" (p. 409).

Cabe destacar el papel central que jugó la Revolución Francesa dentro de esta movilidad de recursos libres; pues fue allí donde quedaron consolidados los preceptos éticos que respaldarían al naciente liberalismo económico.

Lo anterior, me permite aseverar que la tendencia histórica de la globalización ha sido producto de las relaciones comerciales y obtuvo su expansión con las nuevas formas de producción, de trabajo y de intercambio; mismas, que fueron condiciones propicias para la expansión de los mercados. Esto explica, por qué

\footnotetext{
${ }^{6}$ Lógicamente que no todos los países han instrumentado este modelo, ni al mismo tiempo ni con los mismos postulados; pues también el socialismo tuvo su auge, así como el Estado de bienestar que basó buena parte de sus estrategias en el keynesianismo.

${ }^{7}$ La siguiente cita de Marx es bastante ilustrativa cuando habla de las condiciones concretas que dieron lugar al surgimiento del capitalismo:

Ni el dinero ni la mercancía son de por si capital, como no lo son tampoco los medios de producción ni los artículos de consumo. Necesitan convertirse en capital y para ello han de ocurrir una serie de circunstancias concretas, que pueden resumirse así: han de enfrentarse y entrar en contacto dos clases muy diversas de poseedores de mercancías; de una parte, los propietarios de dinero, medios de producción y artículos de consumo, deseosos de valorizar la suma de valor de su propiedad mediante la compra de fuerza ajena de trabajo; de otra parte, los obreros libres, vendedores de su propia fuerza de trabajo y, por tanto, de su trabajo (Max, 2010, p 447, versión electrónica, PDF).
} 
desde hace ya algún tiempo, se habla de una tendencia globalizadora del capital, demarcada por el individualismo como anclaje central, el cual como ya señalé, es apoyado y respaldo por el Estado. ${ }^{8}$

Pero esta tendencia histórica no sólo debe hallarse en los descubrimientos continentales; sino también y como consecuencia de lo anterior, en el dominio y control de los nuevos territorios, basado primero en una acumulación extensiva del capital y posteriormente en una acumulación intensiva (Marx, 2010).

Hasta aquí me queda claro que la globalización en tanto fenómeno histórico, pasó a ser parte del sistema capitalista de producción, el cual con su expansión logró no sólo perfeccionar las relaciones de mercado; sino también hacer parte de su desarrollo a la cultura y a la política, entre otros aspectos de la vida social. A continuación abordaré algunas reflexiones en torno al aspecto cultural desde una perspectiva global. Debo aclarar que no debemos dar por hecho que la interculturalidad es un fenómeno lineal que se desprende de la globalización. Es decir, si hay efectos pero estos son complejos y diferentes, y esto es precisamente lo interesante en esta parte del ensayo.

\section{Efectos de la globalización en la cultura e identidad de los individuos}

\footnotetext{
${ }^{8}$ Flores y Mariña (2000), señalan que el Estado ha sido fundamental en la expansión del capitalismo. Ambos han constituido los acuerdos necesarios para el funcionamiento normativo del sistema y lanzan la "libertad" como uno de los valores supremos de las nuevas leyes dentro de las relaciones de producción.
} 
Si tuviera que señalar cómo fue que el fenómeno de la globalización comenzó a incorporar a la cultura a su proceso de desarrollo y expansión, sería inobjetable indicar que fue a partir de los procesos de intercambio, ocurridos históricamente entre los individuos. Lógicamente dicho proceso relaciona a una multitud de personas con perfiles económicos, culturales, e ideológicos diferentes, pero con un solo objetivo: el intercambio, mismo que enfrenta a las personas como propietarias de mercancías; por un lado el que posee la mercancía-objeto y por otro lado, el que posee la mercancía-dinero. Al respecto Marx señala:

Las mercancías no pueden acudir ellas solas al mercado, ni cambiarse por sí mismas. Debemos, pues, volver la vista a sus guardianes, a los poseedores de mercancías... Para que estas cosas se relacionen las unas con las otras como mercancías, es necesario que sus guardianes se relacionen entre sí como personas cuyas voluntades moran en aquellos objetos, de tal modo que cada poseedor de una mercancía sólo pueda apoderarse de la de otro por voluntad de éste y desprendiéndose de la suya propia; es decir, por medio de un acto de voluntad común a ambos. (Marx, 2010, p. 59).

$Y$ es que en todo este proceso, además de intercambiar mercancías, los individuos intercambian inexorablemente su cultura; es decir, en tanto que el productor o distribuidor tiene como objeto trasladar las mercancías al consumidor, también traslada (involuntaria o voluntariamente) parte de su cultura, con lo que al paso del tiempo, llega a conformarse lo que hoy conocemos como interculturalidad. No obstante, la interculturalidad es un asunto que debe tratarse con las debidas 
precauciones, pues a diferencia de los intercambios económicos, aquí no podemos homogeneizar, justamente por lo complejo que resultan los procesos de intercambio cultural (Todorov, 1989; Wolf, 1987; Clifford, 1995; Aguirre, 1973 y Canclini, 2009)

En este sentido y tal como lo exponen la mayoría de los autores revisados, la interculturalidad supone hablar de una interconexión de culturas, por lo que sería arriesgado afirmar que la cultura es un fenómeno del ámbito nacional. En todo caso, la cultura puede ser infra o supranacional $y$, al referirse a un conjunto de individuos que comparten una serie de afinidades, no es posible imaginarlos como monoculturales. Además, aunque geográficamente las culturas están imbricadas, unas dentro y sobre de otras, socialmente están delimitadas; es decir, que cada uno de "nosotros" pertenece a distintos subconjuntos de población, ya sea por origen, profesión, edad o simplemente por compartir las mismas preferencias de ocio (Todorov, 1989).

Lo interesante de Todorov es su planteamiento metodológico-epistemológico, pues él considera a la humanidad como diversa e infinita, donde todos los valores son relativos que traspasan fronteras; es decir, que cada sujeto le puede dar un sentido distinto en su aplicación. Por tanto, este es un problema entre la unidad y lo diverso o, en otras palabras: entre lo universal y lo relativo. ${ }^{9}$ Sin embargo, en esta diversidad es posible

\footnotetext{
${ }^{9}$ Una de las categorías que utiliza Todorov en su análisis es el etnocentrismo. En su perspectiva, el etnocentrista cree que sus valores son los valores de todos y no repara en tratar de demostrarlo. Por el contrario el universalista no etnocentrista, se fundamenta en la razón y estaría dispuesto a renunciar a algo que le es familiar para adoptar alguna solución observada en una cultura diferente a la suya.
} 
detectar tendencias de distintos tipos; por ejemplo, las tendencias demográficas que marcan trayectorias temporales y raciales, en este caso se pueden mencionar las migraciones de latinoamericanos a EEUU, así como la migración de africanos a Europa (Wolf, 1987 y Canclini, 2009). Otros ejemplos, lo representan las plantas y animales que han sido diseminados por todo el planeta o las vinculaciones financieras que actualmente tienen lugar entre inversionistas especulativos de distintas regiones del mundo (Wolf, 1987).

Pero no obstante de estos patrones homogeneizadores, el mismo Wolf que coincide con Todorov, sostiene que las culturas no son privativas de los países, ya que dentro de ellos también hay sociedades que se entrelazan y, por tanto, no debemos tratarlas como objetos, de lo contrario correríamos el riesgo de crear un modelo semejante a una mesa de juego donde las culturas serían las bolas de billar que se moverían sin hibridarse. De manera que no hay "pureza" en las culturas, ni si quiera las culturas indígenas de Latinoamérica. Por ejemplo cuando Aguirre (1973) se refiere a la colonización de América, señala que el mestizaje cultural entre la madre patria y la población de América se dio a través de un proceso que atendió preferentemente los intereses económicos de España. ${ }^{10}$

Pero aunque el trabajo de Aguirre se centra en la dominación y dependencia entre España y Latinoamérica, es menester señalar que también los europeos se han llevado parte de la cultura de nosotros. Al respecto, el

\footnotetext{
${ }^{10}$ En este estudio Aguirre (1973) analiza seis aspectos que determinaron y configuraron las nuevas formas de interacción cultural en América Latina. Estos aspectos son: la segregación racial, el control político, la dependencia económica, las diferencias de trato, el mantenimiento de la distancia social y la acción evangélica.
} 
trabajo de Mintz (1996) sobre la producción, consumo y exportación del azúcar en Puerto Rico, es una interesante aportación para hablar del intercambio cultural, porque ilustra cómo los ingleses poco a poco fueron tomando predilección por este alimento, con lo cual se entrelazaron una serie de aspectos culturales entre estos pueblos.

Otro de los trabajos que aborda el asunto de la interpretación de las culturas es el que realizó Clifford (1995). En esta investigación él utiliza distintas analogías como el juego y el drama para analizar los comportamientos sociales. Por ejemplo, al citar a Erving Goffman plantea cómo la dramaturgia del juego nos lleva a considerar la vida como un conjunto de estrategias en la que podemos ganar o perder, de acuerdo con el roll que nos toca jugar. ${ }^{11}$ Otra de las analogías que usa Clifford es el texto, donde señala que analizar la conducta humana a través del escritor y el lector, puede resultar no tan natural como hacerlo a través del drama o del juego. Y es que los textos reúnen una serie de símbolos que forman expresiones y transmiten mensajes, los cuales son interpretados de forma diferente en distintos contextos.

Junto a estas analogías que nos hablan de las múltiples formas en que se comunican los individuos, también existe otra forma de comunicación que en situaciones y contextos diferentes, adquiere otros significados. Me refiero concretamente al lenguaje silencioso. Hall (1989) en su trabajo del mismo nombre aborda con acuciosidad, aspectos del lenguaje que tienen distintos significados

\footnotetext{
${ }^{11}$ En otra parte de la investigación, Clifford (1995) señala como "el mundo no es más que un escenario y nosotros no somos sino pobres actores que se pavonean.(p. 39)"
} 
según el origen social de los individuos. Por ejemplo, dedica una parte importante de su trabajo al análisis del uso y manejo del tiempo y del espacio como medios de comunicación. Probablemente el mensaje central de Hall en su obra es que trata de transmitirnos que debemos aprender a comprender la parte <no consciente $>$ de la comunicación. Más aun, en estos tiempos donde el lenguaje tiende a abreviarse, el lenguaje silencioso se vuelve particularmente importante. ${ }^{12}$

Los planteamientos que hasta aquí he presentado, me permiten aseverar que la cultura es un asunto sumamente complejo y que en la actualidad es difícil hablar de pureza en ellas, puesto cada una está formada por un conjunto de relaciones, cuya naturaleza es compleja en sí misma. Probablemente a lo más que se puede aspirar, es a la identificación de algunos rasgos que las caracterizan y en las que pueden converger determinadas poblaciones. Al respecto podrían citarse varios casos; por ejemplo, el tequila y la tortilla en el caso de los mexicanos, aunque estos productos no sean privativos de México; el ron y los puros en el caso de los cubanos, el vodka en el caso de los rusos, etc. Seguramente por ello es que Canclini (2009) eligió el concepto de hibridación para referirse a las identidades y a la multiculturalidad, lógicamente con la aclaración de que hibridar no es sinónimo de fusionar o mezclar, puesto que más allá de una homogeneización, la hibridación supone hablar de una serie de contradicciones

\footnotetext{
12 Hay una gran variedad en que se puede apreciar el lenguaje silencioso, desde ademanes hasta los movimientos gesticulares. Por ejemplo, fruncir una o ambas cejas, levantar un hombro o ambos, todo ello orienta y envía mensajes. Así mismo, el manejo del espacio igual es un medio de comunicación, por ejemplo, un extraño debe mantener una distancia de nosotros de por lo menos un metro.
} 
complejas que requieren la explicación de los científicos sociales.

\section{Globalización, educación y condiciones de empleabilidad}

En esta última parte del ensayo expongo algunas reflexiones principales relacionadas con los efectos de la globalización en el ámbito educativo y, particularmente con los efectos en torno a las competencias y condiciones de empleabilidad que deben poseer los egresados de educación superior, cuando inician su proceso de inserción en el mercado laboral.

Por fortuna la literatura sobre esta temática es bastante amplia, y mejor aún, en la actualidad hay una serie de líneas de investigación que han avanzado y profundizado en estudios sobre la educación superior, ya sea desde la perspectiva económica, política, ideológica, social o administrativa, pero todos ellos vinculados al fenómeno de la globalización.

Así como la economía de mercado ha transformado las relaciones sociales de producción, así también, los Estados Nacionales se han transformado e inexorablemente, estos cambios han afectado a las instituciones de educación superior (IES). Esto implica avanzar hacia nuevos procesos modernizadores basados en una creciente flexibilización de las actividades; lo cual reafirma la capacidad del capital para marcar la pauta por donde han de transitar los medios que utiliza en su proceso de valorización. Lógicamente es el Estado el que facilita los medios para este propósito $y$, en este proceso 
el Estado mismo se transforma y hace lo mismo con sus instituciones (Castells, 1996, citado por Ordorika, 2006; Noriega, 2000).

En este sentido, tales reacomodos originan cambios en la política fiscal $y$, en consecuencia, cambios en la disposición y uso de los recursos. Esto ha implica espacialmente una reducción del presupuesto, particularmente para la educación superior, $\mathrm{y}$ por otro lado, una mayor vigilancia para su asignación.

Lo anterior deriva en una exigencia para las IES en busca de la eficiencia en el uso de sus recursos en varios sentidos: primero, una desregulación de las condiciones de trabajo de su personal; segundo, en el caso de las IES públicas una disminución en la matricula, lo cual ha propiciado el crecimiento de las IES privadas; tercero y como consecuencia de los puntos anteriores, una migración de docentes de las IES públicas a las IES privadas; cuarto, autogeneración de recursos propios, como por ejemplo el desarrollo de centros de negocios o empresas incubadoras (Schugurensky, 1998). Como producto de lo anterior, las IES compiten por la excelencia; ahora sus programas académicos son evaluados y certificados por una institución externa. Tales certificaciones además de captar recursos para la institución, también generan un reposicionamiento en el mercado educativo y esto, es otro elemento que permite atraer matricula cautiva. Como se observa, el propósito es alcanzar el más elevado nivel de competitividad de

\footnotetext{
${ }^{13}$ El uso racional de los recursos y con ello su optimización, por fin se ejerce en las instituciones de gobierno y las IES no escapan a ello. Esto no quiere decir, que antes no existieran las auditorias, más bien significa que hoy las universidades deben ser más eficientes, no sólo en el uso del presupuesto; sino también en su producción de egresados.
} 
acuerdo con la lógica del mercado, de manera que combinado con el uso de la tecnología y la ciencia, las IES dispongan de un alto nivel de recursos humanos, pero así mismo, también formen egresados de alta calidad (Noriega, 2000).

Por otra parte, si coincidimos en que el origen de estos cambios se encuentran en la relaciones de producción, cuya inducción es a través del mercado. También es menester preguntarse cuáles son los medios y cuál es el fin de dichos cambios y, aquí es donde se podría estar o no de acuerdo con los elementos que se señalen. De hecho hay divergencia significativa al respecto. Por ejemplo, autores como Beck (1998), Castell (1996), Flores y Mariña (2000), Schugurensky (1998) y Noriega (2000) entre otros, coinciden al señalar que el gran objetivo del capitalismo contemporáneo, expresado en el modelo neoliberal, el cual incluye al sector educativo, es la búsqueda de nuevos vehículos de acumulación de capital. ${ }^{14}$ De ahí que exista un patrón de hegemonía ideológica, al cual queda supeditada la educación superior y es promovido tanto por gobiernos como por instituciones supranacionales que proyectan un modelo ideológico internacional (Dettmer, 2004; Ordorika, 2006; Marginsón y Ordorika, en prensa).

Ahora bien, en cuanto a los medios que se utilizan para conseguir tal objetivo se encuentra justamente este modelo ideológico internacional, que busca la homogeneización y convergencia de los sistemas educativos. Ejemplo de este proceso de convergencia son

\footnotetext{
${ }^{14}$ El capital penetra, permea y modela sus propios cuadros de formación del factor humano del que dispondrá posteriormente. La gran mayoría de las universidades de EEUU son ejemplo de ello y en el caso de México, el Tecnológico de Monterrey.
} 
los exámenes $\mathrm{PISA}^{15}$ que promueve y aplica la OCDE. Otro ejemplo son los programas de ajuste estructural, especialmente en materia educativa, que promueve el Banco Mundial y para los cuales otorga financiamiento y asesoría a los gobiernos periféricos, para elaborar políticas educativas (Noriega, 2000). ${ }^{16}$

Junto a este proceso de convergencia, otro medio que se utiliza es la desconcentración educativa; es decir, que las IES ya no estén concentradas en un solo territorio, sino que su oferta educativa se diversifique y se disemine a lo largo del área de influencia. ${ }^{17}$ Esto abre la posibilidad de incrementar eficientemente la cobertura y, así mismo, brindar una educación de calidad a más estudiantes.

Otro medio importante en este proceso de modernización educativa, es la homogeneización de los planes de estudio, mismo que está ligado al fenómeno de la convergencia, pues procura que tales programas estén expresados en un modelo educativo que comparta los mismos principios y estrategias. Algunas de las estrategias son: promover la movilidad estudiantil y docente entre universidades identificadas al mismo modelo, impulsar líneas de investigación comparada en distintas áreas del conocimiento, disponer de infraestructura y equipamiento tecnológico, impulsar las

\footnotetext{
${ }^{15}$ Por sus siglas en inglés PISA significa "Proyecto Internacional para la Producción de Indicadores de Resultados Educativos de los Alumnos", "Programme for Indicators of Student Achievement".

${ }^{16}$ El Banco Mundial señala que las políticas educativas a las cuales asesora, deben adecuarse a las circunstancias de los países; sin embargo, es posible detectar condicionamiento de recursos cuando los gobiernos locales no acatan las "sugerencias" de diseño y estructura de dichas políticas.

${ }^{17}$ Junto a esto, también hay que señalar el proceso de desconcentración educativa básica que ahora instrumentan los gobiernos como mecanismo para incentivar la eficiencia en los indicadores del logro educativo (Noriega, 2000).
} 
estancias y prácticas profesionales orientadas al mercado laboral, entre otras (Dettmer, 2004; Noriega, 2000; Marginsón y Ordorika, en prensa). ${ }^{18}$

Cabe aclarar que las estrategias mencionadas se orientan a la formación y desarrollo de competencias profesionales, mismas que son fundamentales para operar un mercado laboral, que como señalé al principio, es dinámico y cambiante (OEl, 2000). Esta es desde mi punto de vista, la principal justificación que encierra el nuevo proyecto de reforma educativa, que como hemos visto, es de alcance mundial y hegemónico, liderado principalmente por EEUU e instituciones supranacionales. En este sentido, las competencias y habilidades profesionales son útiles para configurar lo que serán las condiciones de empleabilidad de los egresados de las IES; es decir, son las que le posibilitarán competir por un puesto en el mercado de trabajo. No obstante, las condiciones de empleabilidad, no garantizan en lo más mínimo, la estabilidad en un empleo, pero sí posibilita competir por puestos de trabajo mejor remunerados. De manera que, la flexibilidad lejos de ser un obstáculo, es una condición necesaria para el desarrollo de las competencias profesionales y las condiciones de empleabilidad, en un modelo basado en la libre movilidad laboral y académica.

\footnotetext{
${ }^{18}$ Es menester señalar que la movilidad académica es un asunto que también está relacionada con la desconcentración educativa, pues a través de convenios y acuerdos entre IES, ahora es posible que un alumno que estudia administración en México, concluya sus estudios en otro país, con lo que el proceso de formación profesional del estudiante es compartido, lo cual puede mejorar la calidad del egresado y, en consecuencia potenciar sus capacidades y habilidades. No obstante, estos programas de movilidad tienen la desventaja de generar contradicciones, ya que las condiciones históricas y de desarrollo difieren entre países y al interior de ellos mismos.
} 
Es así que en un modelo de libre movilidad, los mercados de trabajo demandan un factor humano altamente capacitado, donde las habilidades en conocimiento se superponen a las habilidades físicas. Hoy las competencias cognitivas, sociales y tecnológicas son fundamentales para insertarse en condiciones favorables al mercado laboral. Esto es, que los individuos cuenten con una capacidad de adaptación rápida a estructuras organizacionales menos jerarquizadas, con habilidades para el desarrollar actividades variadas y diferenciadas que le posibiliten visualizar los procesos de una manera integral y no parcial y rutinaria (OEI, 2000).

De hecho, la formación profesional y dotación de competencias tiene como objetivo facilitar el proceso de inserción de los egresados al mercado laboral. Cabe aclarar que la formación de tales competencias difiere según las cualidades del egresado y del tipo de IES. No obstante, algunos aspectos que se consideran esenciales en esta formación de competencias y que determinarán la empleabilidad del egresado, son poseer título profesional, dominar una lengua extranjera, experiencia profesional y el dominio de las TIC'S, (Gómez, 2006).

Hasta aquí, he planteado algunas características y efectos que este llamado proceso de globalización ha provocado en el contexto educativo, lógicamente lo he hecho desde una perspectiva general, mundial y sólo en algunos casos nacional o regional.

\section{Conclusiones}


El artículo aquí presentado nos lleva a comprender que los efectos de la globalización son múltiples, variados e inacabados. Queda claro que la temática es muy rica y propicia para la discusión, y en la cual estoy convencido que se pueden hacer aportes importantes, no sólo para comprender el fenómeno desde lo local; sino también para construir propuestas que contribuyan con el mejoramiento del proceso de inserción de los egresados de educación superior al mercado laboral en una perspectiva global.

De cualquier manera, me parece que en estos tiempos de intercambios, de redes académicas, de educación virtual y a distancia, el proceso de convergencia y desconcentración educativa no es la panacea, ya que al estar lleno de buenos propósitos, también encierra una serie de contradicciones y excluye a muchos individuos del proceso de formación educativa. Además como lo señala Noriega (2000), la flexibilización educativa y del mercado laboral ha generado más problemas que beneficios sociales a los países periféricos, entre ellos, el desempleo y subempleo profesional, así como la expansión del sector informal de la economía. No obstante, la globalización educativa es un proceso irreversible, por tanto, tenemos que aprender a convivir con ella y sacar el mejor de los beneficios en estos mercados tan competidos.

\section{Fuentes de CONSULtA}

- AGUIRRE, B. [1973]. Regiones de refugio, el desarrollo de la comunidad y el proceso dominical 
mestizoamérica, $2^{\mathrm{a}}$ edición. Instituto Nacional Indigenista, México.

- BECK, U. [1998]. ¿Qué es la globalización?, Ed., Paidos, Barcelona, España.

- BRAUDEL, F. [1986] La dinámica del capitalismo, México, FCE.

- CANCLINI, G. [2009]. Culturas híbridas, estrategias para entrar y salir de la modernidad, Debolsillo, México.

- CASTELLS, M. [1996]. The rise of the nerwork society. Cambridge, Mas: Blackwell Publishers.

- CLIFFORD, J. [1995]. Dilemas de la cultura. Antropología, literatura y arte desde la perspectiva posmoderna, Ed., Gedisa, España.

- COELLO, H. (2009). Ensayo sobre empleabilidad, en línea: http://helkyncoello.wordpress.com/2009/05/26/ensa yo-sobre-empleabilidad/, consultado el 2 de abril de 2010.

- DE LA GARZA, E. (2000). "La flexibilidad del trabajo en América Latina", en Tratado Latinoamericano de Sociología del Trabajo, Enrique de la Garza Toledo, (Coordinador), El Colegio de México, FLACSO, UAM, FCE.

- DETTMER, J. [2004]. Globalización, Convergencia y Diversificación de la Educación Superior: una 
revisión conceptual, en revista de la Educación Superior, N. 32, pp. 1-24.

- FERRER, A. [1996]. Historia de la globalización: orígenes del orden económico mundial, Buenos Aires, FCE.

- FLORES, O. y A. Mariña (2000). Crítica de la globalidad: dominación y liberación en nuestro tiempo, FCE, ISBN 968-16-5994-5, México, DF.

- GÓMEZ, G. (2006). "El trabajo de los universitarios", en Competencias y habilidades profesionales para universitarios, Carlos J. Van-der Hofstadt Román y José María Gómez Grass, editores, editorial Días de Santos, Mardid, ISBN 847978-796-1, PP.7-37.

- HALL, E. [1989]. El lenguaje silencioso, CONACULTA-Alianza Editorial México.

- LLOBEREA, J. [1990]. La identidad de la antropología, $2^{\text {a }}$ edición, ed., Anagrama, ISBN 10: 8433913409 , España.

- MARGINSON, S. e I. Ordorika [en prensa]. "EI central volumen de la fuerza. Global hegemony in higher education and research", en The Transformation of Public Research Universities: Shaping and International and Interdisciplinary Research Agenda for the Social Sciences, eds. D Rhoten y C. J. Calhoun. New York: SSRC, PDF. 
- MARTUSCELLI, J. y C. Martínez (2002). "Problemas de la pertinencia de la educación superior en el mercado laboral", ponencia presentada en el Congreso Retos y Expectativas de la Universidad, celebrado del 6 al 9 de noviembre en Ixtapan de la Sal: ANUIES/UAM.

- MARX, C. [2010] El capital, vol. I, sexta reimpresión, FCE. Versión electrónica en línea: http://www.formacion.psuv.org.ve/wpcontent/uploads/2010/10/51El-Capital-KarlMarx.pdf, consultado el 17 de febrero de 2010.

- MINTZ, S. [1996]. Dulzura y poder. El lugar del azúcar en la historia moderna, Siglo XXI, Editores, México.

- NORIEGA, C. [2000]. Las reformas educativas y su financiamiento en el contexto de la globalización: el caso de México, 1982-1994, UPN, Plaza y Valdés, México, D.F.

- ORGANIZACIÓN DE ESTADOS IBEROAMERICANOS, OEI [2000]. Análisis ocupacional y funcional del trabajo, Consejo de Normalización y Certificación de Competencia Laboral [CONOCER], ISBN: 84-7666-089-8, Madrid, España. En línea: http://www.oei.es/oeivirt/fp/iberfop03.htm, consultado el 15 de agosto de 2010.

- ORDORIKA, I. [2006]. "Educación Superior y Globalización: las universidades públicas frente a 
una nueva hegemonía", en revista de investigación social Andamios, México, pp. 31-48.

- RUESGA, M. y C. Murayama (2000). "Desempleo y precariedad laboral en Europa: Referencia al caso español", en revista Trabajo, año 2, No 3, UAM, UNAM Y PYV.

- SCHUGURENSKY, D. [1998]. "La restructuración de la educación superior en la era de la globalización: ¿Hacia un modelo heterónomo?”, en Educación, democracia y desarrollo en el fin de siglo, Ed., Siglo XXI, editores, México.

- TODOROV, T. [2003]. Nosotros y los otros, Ed., Siglo XXI, $3^{\text {era }}$ reimpresión, México.

- WALLERSTEIN, I. [1990]. "Análisis de los sistemas mundiales", en Anthony Guidens et al, La teoría social hoy, ed., Alianza Universidad, España.

- WOLF, E. [1987]. Europa y la gente sin historia, FCE, México. 